

\section{Educación y nuevos medios: ¿Convergencias ignoradas o previstas?}

DOI: 10.15213/REDES.N12.P18

\section{ALFONSO GUTIÉRREZ MARTÍN}

El mero enunciado del título de este monográfico, "Tecnologías y Educación", podría llevarnos ya al error de considerar dos realidades independientes de partida: "tecnologías" y "educación", y, por lo tanto, a la posibilidad de considerar una educación sin tecnología. La tecnología en su sentido más amplio de "conjunto de teorías y de técnicas que permiten el aprovechamiento práctico del conocimiento científico" (RAE) ha sido siempre un componente básico de la educación. Las tecnologías de la información y comunicación (TIC) en concreto también pueden considerarse ya parte integrante del proceso educativo. Lejos queda ya la dicotomía de Eco (1965) sobre los apocalípticos, que sobredimensionan los aspectos negativos de los medios y la tecnología, y los integrados, para quienes solo parecen existir ventajas con la llegada de los nuevos medios a nuestras vidas. Cuando los medios de masas y las tecnologías de la información se implantaron en el siglo pasado, desde el mundo de la educación se valoraba la conveniencia de incorporar o no los entonces nuevos medios a las aulas. Por un lado se consideraba la educación como sistema más bien cerrado y por el otro, y fuera del sistema educativo, las TIC. Desde el mundo de la educación, que nunca se ha caracterizado por su apertura, se planteaba entonces la integración curricular de las nuevas tecnologías.

Hoy día la omnipresencia de la tecnología digital en prácticamente todos los aspectos de nuestras vidas, incluida, por supuesto, la educación, deja sin sentido ese planteamiento. La duda ahora no es si la tecnología debe o no estar presente en los procesos educativos, sino cómo debe de estar, cómo queremos que esté para que contribuya mejor a la formación integral de las personas y sociedades. La convergencia de TIC y aprendizaje fuera de la escuela, tanto en educación informal como no formal, hace incuestionablemente necesaria esa misma convergencia dentro de las aulas de educación formal. Negar la evidencia, negar esta convergencia entre digitalización y educación sería como pretender circular hoy día con coches de caballos por la contaminación que provocan los coches.

Paralelas a esta convergencia o hibridación de educación y medios, encontramos otras convergencias que no solo no podemos ignorar sino que, como 
educadores responsables, tenemos que prever. Algunas de ellas se irán poniendo de manifiesto en este monográfico. Como primera convergencia nos referimos a lo que podría ser la fusión que se está llevando a cabo de la educación formal con la informal y con modelos de enseñanza no formal. Las fronteras entre los distintos entornos de aprendizaje se difuminan y se concibe la educación como un proceso a lo largo de toda la vida que, lógicamente, se lleva a cabo tanto dentro como fuera del aula. Así lo manifiestan más adelante Mari Carmen Caldeiro Pedreira y José Ignacio AguadedGómez Gómez en su artículo sobre la competencia mediática como forma de expresión crítica de nativos e inmigrantes digitales. Estos autores parten del interés por conciliar los espacios académico y social; ponen de manifiesto la apertura de los espacios de aprendizaje y la hibridación de los mismos a la que ha dado lugar la continua emergencia de dispositivos tecnológicos, y proponen el desarrollo de la competencia crítica que permita al ciudadano interactuar y comunicarse de manera autónoma.

Inmaculada Sánchez-Labella Martín, por su parte, pone de manifiesto la importancia de la tecnología, de las tablets en particular, en la educación informal. Destaca en su artículo el hecho incuestionable de que actualmente casi el ochenta por ciento de los niños y niñas utilizan frecuentemente este nuevo dispositivo para entretenerse el cual - según la autora - les concede autonomía y libertad para acceder a multitud de contenidos. La educación y el aprendizaje cada vez se producen más (no sé si mejor) de forma vicaria o mediada por una pantalla. Como señala esta autora, "con el surgimiento y el desarrollo de Internet la tecnología se ha convertido en la protagonista de las sociedades desarrolladas presentando un panorama el que se cruza el plano de lo educativo y lo tecnológico". Si seguimos ignorando la convergencia entre tecnología y educación, entre los distintos entornos de aprendizaje, la escuela irá perdiendo protagonismo en la vida de los niños. Si queremos preparar adecuadamente a las futuras generaciones, no podemos limitar nuestra acción educativa a los muros del aula; deberíamos, como señala SánchezLabella, asumir "el compromiso por desarrollar contenidos infantiles que tengan la capacidad de educar a través del entretenimiento".

Gabriel Lyra Chaves y Daniela Favaro Garrossini ponen también de manifiesto el paralelismo ya insostenible entre la educación formal y la escuela paralela de los medios de comunicación. Analizan estos autores las diferencias entre una y otra en lo que se refiere al tratamiento de la información, y destacan las diferencias entre el "razonamiento discursivo" de la escuela y el "razonamiento narrativo", así como las posibles ventajas de una convergencia entre ambos. 
La convergencia de entornos y medios de aprendizaje no constituye, lógicamente, un hecho puntual ni tiene lugar en una época de la vida determinada, sino que, como y hemos apuntado, aprendemos dentro y fuera de la escuela a lo largo de toda la vida. Tanto la educación mediática como la competencia digital suponen conocimientos y destrezas necesarios en la sociedad de la información para las personas de cualquier edad. Así lo reflejan Rocío Cruz Díaz, Sara Román García y Francisco Pavón Rabasco en su aportación sobre el uso de las tecnologías y la competencia mediática en las personas mayores.

Con el análisis de los comentarios sobre la lectura que los usuarios adolescentes españoles manifiestan en la red social Twitter, Alba Torrego González nos muestra cómo el educando vive sus diferentes entornos de aprendizaje como interconectados entre sí, cómo utiliza las redes sociales para manifestar su gusto por la lectura y sus preferencias literarias. Ahora bien, podrían resultar preocupantes las observaciones de la autora cuando señala que del análisis se desprende que la mayoría de la población adolescente usuaria de Twitter que manifiesta su gusto por la lectura en las redes sociales hace referencia únicamente a best-sellers juveniles. Son escasas las alusiones a las obras literarias que suelen abordarse como lectura obligatoria en la escuela reglada. Concluye la autora que, "desde un punto de vista didáctico, es necesario conocer las preferencias lectoras de los jóvenes y su visión de la literatura para plantear posibles itinerarios lectores que acerquen las obras literarias a los adolescentes". Sería también necesario plantear una mayor consideración de la "cultura popular" en los currículos escolares oficiales.

Otra de las convergencias que queremos aquí plantear es la de enseñar "con" y enseñar "sobre" los medios. Proponemos una integración global de las TIC y los medios en la educación que supere la vieja dicotomía de la tecnología educativa (enseñanza "con" recursos tecnológicos), por una pate; y la educación para los medios o educación mediática (enseñanza "sobre" los medios) por la otra. No debemos caer en el error de considerar las TIC en la enseñanza simplemente como recursos didácticos, como meras herramientas transparentes con las que enseñar y aprender. Los medios digitales llevan su propio mensaje y, además de recursos, han de ser considerados objeto o materia de estudio de especial relevancia en la sociedad dela información. La educación mediática incluye como inseparables el estudio y la utilización de los nuevos medios en los procesos de enseñanza-aprendizaje.

Históricamente la tecnología educativa ha precedido a la educación mediática o alfabetización digital en las escuelas. El uso del vídeo, el ordenador, Internet, las redes sociales y de las tecnologías en general como recursos didácticos, como herramientas para favorecer la enseñanza de los conteni- 
dos curriculares, ha supuesto tradicionalmente el primer paso de integración de las tecnologías y los medios de comunicación en los centros educativos. En este monográfico contamos con algunos interesantes ejemplos del uso de las TIC como recursos didácticos. María José Arroyo González e Ignacio Berzosa Ramos, por ejemplo, abordan en su artículo el potencial de los blogs en la enseñanza secundaria, y más en concreto, en la asignatura de "Ciencias para el Mundo Contemporáneo" del Bachillerato español, y nos sugieren nuevas posibilidades de explotación didáctica.

Neves Dias Francisco y Silva e Meirelles, por su parte, analizan el potencial de las TIC en la educación a distancia, y centran su estudio en el desarrollo de competencias tecnológicas por parte de los usuarios. Con su investigación llevada a cabo en una institución brasileña de educación superior, demuestran que la introducción de la tecnología en la educación a distancia conlleva cambios significativos tanto en el profesorado como en la propia institución.

También Julio César Mateus aborda el cambio que las tecnologías producen en el profesorado. En este caso se trata de docentes de escuelas públicas peruanas. Comenzábamos esta introducción presentado la presencia de la tecnología en la educación como inevitable, lo que no quiere decir, como veremos más adelante, que el modelo de integración dominante sea incuestionable. Mateus destaca el malestar del profesorado peruano que se ve obligado a utilizar las TIC por presión social, sin convencimiento y sin suficiente preparación, más como víctimas del discurso dominante que como beneficiarios del progreso tecnológico: "Comprobamos que la llegada de TIC a estos contextos se da por imposición y que la presión exógena limita la oportunidad de una integración adecuada al crear un clima de permanente tensión. Finalmente, concluimos que si bien las TIC son percibidas como imprescindibles, los docentes no tienen certeza de cómo deben ser explotadas pedagógicamente ni cuál es el sentido de su presencia".

Como ya hemos manifestado, además de estudiar y aprender con los medios, en la escuela del siglo XXI se ha de abordar el análisis crítico y el estudio de las tecnologías de la información y de la comunicación. La alfabetización necesaria para esta sociedad de la información en la que estamos inmersos no puede pasar por alto ni la presencia ni la influencia de los nuevos medios en nuestro desarrollo social, económico y cultural. La educación básica a la que cualquier individuo tiene derecho, si ha de ser una preparación para la vida, es hoy día una "educación para los medios", una educación "mediática".

En un modelo de educación global, donde convergen el uso y el estudio de los medios, convergen también los distintos saberes que en los sistemas 
educativos tradicionales se han intentado separar en distintas asignaturas. Esta "departamentalización" de la ciencia cada vez tiene menos sentido en un mundo interconectado donde el saber no se sujeta ni con las cubiertas de los libros ni con los muros de la Academia. Los nuevos programas de educación básica deberían ir en la línea de confluencia y fusión de asignaturas, materias y entornos que propone Soraya Calvo González en este monográfico. La autora nos expone su experiencia de incorporar la alfabetización mediática crítica en un programa de educación sexual para educación secundaria obligatoria. Parte Calvo de una investigación orientada a conocer el uso cotidiano que los y las jóvenes de entre 14 y 16 años hacen de las redes sociales para comunicarse emocional y afectivamente, y elabora una propuesta para trabajar en la educación formal aspectos como privacidad e intimidad, gestión de relaciones personales o emocionales, empoderamiento y uso crítico de las TIC, entre otros.

Parece comúnmente admitido que el fin último de la educación es la "preparación para la vida" y a lo largo de toda la vida. La educación para los medios o educación mediática, podría, por tanto, considerarse como una necesidad derivada de la presencia de los medios de comunicación en nuestro quehacer cotidiano, de los medios como parte de nuestra vida, como así manifiestan varios autores en este monográfico.

A medida que cambia la sociedad, cambian las formas de vida y las competencias necesarias para vivir libre y dignamente en cada época. La lecto-escritura, incuestionable e incuestionada hoy día, no se consideró una necesidad educativa hasta la aparición de la imprenta y la posterior generalización de la letra impresa. La importancia del lenguaje verbal escrito dio lugar a la necesidad de aprender a leer y a escribir, y la alfabetización verbal ha sido desde entonces (y sigue siendo) la principal preocupación de los sistemas educativos. Debido a la importancia que en el siglo XX adquieren el lenguaje audiovisual y los medios de comunicación, parecía lógico pensar que a la alfabetización verbal había que añadir algún tipo de alfabetización visual o audiovisual. Por Alfabetización Visual (Visual Literacy) se entiende la capacidad de leer y escribir imágenes, y de pensar y aprender en imágenes. También se ha definido como la capacidad tanto de interpretar como de crear imágenes en varios medios con el fin de comunicar con eficacia.

Con la Alfabetización para los Medios (Media Literacy) se intenta ayudar a los educandos a desarrollar una comprensión crítica de la naturaleza de los medios de masas, de las técnicas que utilizan y del impacto que producen. Más concretamente es una educación cuyo principal objetivo es aumentar el nivel de comprensión y disfrute de los estudiantes con los medios, favorecer 
la comprensión de cómo los medios producen significados, cómo se organizan, cómo construyen su propia realidad. Todo ello sin olvidar las destrezas y conocimientos necesarios para crear productos mediáticos. La alfabetización para los medios ha sido también definida como la capacidad de acceder, analizar y producir comunicación de varias formas.

En muchos casos, y ahora más con la llegada de la digitalización de la información y de múltiples dispositivos, el estudio de los medios se limita al estudio de su funcionamiento y manejo. A veces incluso se confunde la educación para los medios con la capacitación técnica para el uso de las TIC, de las redes de ordenadores y de distintos dispositivos de edición de vídeo, texto e imagen, etc. Esta preparación técnica de los usuarios de medios también ha sido denominada por algunos autores como "alfabetización digital". Diego Apolo Buenaño, Marc Bayés Gil y Andrés Hermann Acosta nos advierten en su artículo del reduccionismo que supone esta concepción, y nos plantean "la necesidad de emprender procesos de alfabetización digital que no sólo se circunscriban al manejo artefactual de la red internet y de los ordenadores, sino también al desarrollo del pensamiento crítico y creativo que se encuentra en esta nueva ecología de medios". Analizan estos autores los cambios educativos derivados de la lectura digital, una lectura que ya no es tan lineal o secuencial como en los textos o documentos audiovisuales no interactivos. La convergencia de lenguajes y medios en el ciberespacio, la convergencia de textos, imágenes y sonidos en documentos multimedia interactivos, exige una convergencia de los distintos tipos de alfabetizaciones anteriormente señalados.

Tyner, Gutiérrez y Torrego (2015) analizan la variedad de espacios de aprendizajes reales y virtuales, y la continuidad y prolongación de esos aprendizajes en el tiempo y el espacio. Abordan, así mismo las convergencias entre la educación dentro y fuera del aula; entre la educación y la comunicación, y entre distintas alfabetizaciones para, en consonancia con esas convergencias, proponer un modelo comprehensivo de formación básica o de alfabetización múltiple como tarea de todos. Desde cualquier tipo de acción educativa debemos de ser conscientes de la cultura de la convergencia que caracteriza estos comienzos del siglo XXI, y abordar desde la convergencia modelos de educación abierta donde los medios y la tecnología digital estarán inevitablemente presentes.

La inevitabilidad de la tecnología en la educación no supone la aceptación incondicional de cualquier modelo de integración. Muy al contrario, es precisamente la omnipresencia y trascendencia de los nuevos medios lo que, como educadores, nos exige una actitud crítica y reflexiva a la hora de valorar, utilizar e integrar las TIC en una educación mediática global. 
PRESENTACIÓN: EDUCACIÓN Y NUEVOS MEDIOS: ¿CONVERGENCIAS IGNORADAS O PREVISTAS?

\section{BIBLIOGRAFía}

JENKINS, H. (2006): Convergence Culture: When new and old media collide. New York: New York University.

TYNER, K., GUTIÉRREZ, A., \& TORREGO, A. (2015). Multialfabetización sin muros en la era de la convergencia. La competencia digital $y$ «la cultura del hacer» como revulsivos para una educación continua. Profesorado, 19(2), 41-56. 